\title{
Neurogenesis in the Dentate Gyrus of the Adult Tree Shrew Is Regulated by Psychosocial Stress and NMDA Receptor Activation
}

\author{
Elizabeth Gould, ${ }^{1}$ Bruce S. McEwen, ${ }^{1}$ Patima Tanapat, ${ }^{1}$ Liisa A. M. Galea, ${ }^{1}$ and Eberhard Fuchs ${ }^{2}$ \\ 1The Rockefeller University, New York, New York 10021, and 2The German Primate Center, 37077 Göttingen, Germany
}

These studies were designed to determine whether adult neurogenesis occurs in the dentate gyrus of the tree shrew, an animal phylogenetically between insectivores and primates, and to explore the possibility that this process is regulated by stressful experiences and NMDA receptor activation. We performed immunohistochemistry for cell-specific markers and the thymidine analog bromodeoxyuridine (BrdU), a marker of DNA synthesis that labels proliferating cells and their progeny, on the brains of adult tree shrews subjected to psychosocial stress or NMDA receptor antagonist treatment. Cells that incorporated BrdU in the dentate gyrus of adult tree shrews were primarily located in the subgranular zone, had morphological characteristics of granule neuron precursors, and appeared to divide within $24 \mathrm{hr}$ after BrdU injection. Three weeks after BrdU injection, BrdU-labeled cells had neuronal morphology, expressed the neuronal marker neuron specific enolase, and were incor- porated into the granule cell layer. Vimentin-immunoreactive radial glia were observed in the dentate gyrus with cell bodies in the subgranular zone and processes extending into the granule cell layer.

Exposure to acute psychosocial stress resulted in a rapid decrease in the number of BrdU-labeled cells in the dentate gyrus. In contrast, blockade of NMDA receptors, with the NMDA receptor antagonist MK-801, resulted in an increase in the number of BrdU-labeled cells in the dentate gyrus. These results indicate that adult neurogenesis occurs in the tree shrew dentate gyrus and is regulated by a stressful experience and NMDA receptor activation. Furthermore, we suggest that these characteristics may be common to most mammalian species.

Key words: neurogenesis; tree shrew; psychosocial stress; granule neurons; dentate gyrus; NMDA receptors
In most brain regions, the production of neurons is typically confined to a discrete developmental period. In contrast, granule neurons of the dentate gyrus are produced during an extended period that begins during gestation and spans well into the postnatal period in all mammalian species that have been examined, including the mouse, rat, guinea pig, rabbit, cat, and rhesus monkey (Angevine, 1965; Altman and Das, 1967; Schlessinger et al., 1975; Rakic and Nowakowski, 1981; Gueneau et al., 1982; Wyss and Sripanidkulchai, 1985). In the rat, granule neurons continue to be produced in adulthood from a pool of precursor cells that reside within the dentate gyrus (Kaplan and Hinds, 1977; Kaplan and Bell, 1984). The granule neurons produced in adulthood seem to migrate into the granule cell layer along existing radial glia, extend axons, make synaptic contacts, and express neuronal markers (Kaplan and Bell, 1984; Stanfield and Trice, 1988; Cameron et al., 1993; Okano et al., 1993; Kuhn et al., 1996).

The production of granule neurons in the adult rat dentate gyrus has been shown to be suppressed by adrenal steroids (Cameron and Gould, 1994) and excitatory input via the NMDA receptor subtype of glutamate receptors (Cameron et al., 1995). Because both circulating adrenal steroid levels and glutamatemediated excitatory input to the hippocampus are enhanced by stress (Krugers et al., 1993; Moghaddam et al., 1994; Bartanusz et al., 1995), it is possible that stressful experiences naturally mod-

Received Oct. 11, 1996; revised Dec. 3, 1996; accepted Jan. 10, 1997.

This work was supported by National Institute of Mental Health Grant MH52423 and a National Alliance for Research on Schizophrenia and Depression Young Investigator Award (E.G.). We thank Dr. Gabrielle Flugge for assistance with templates.

Correspondence should be addressed to Dr. Elizabeth Gould, Department of Psychology, Green Hall, Princeton University, Princeton, NJ 08544.

Copyright (C) 1997 Society for Neuroscience $0270-6474 / 97 / 172492-07 \$ 05.00 / 0$ ulate the production of granule neurons in the dentate gyrus of adult animals. This possibility is supported by a recent study showing that cell proliferation in the dentate gyrus of adult rats can be suppressed by exposure to predator odor, a naturally aversive experience (Galea et al., 1996).

Although the existence of neurogenesis in the dentate gyrus of adult rhesus monkeys has been dismissed (Eckenhoff and Rakic, 1988), this phenomenon has not been investigated in other species of primates or tree shrews. The present studies were undertaken to determine whether granule cell production and its regulation by stressful experience and excitatory input occur in the dentate gyrus of the adult tree shrew Tupaia belangeri. Tree shrews, which are considered to be phylogenetically between insectivores and primates (Martin, 1990), have been studied extensively in a well characterized model of psychosocial stress. When paired with a same-sex conspecific, tree shrews rapidly establish a potent, enduring dominant/ subordinate relationship that is particularly stressful to the subordinate animal (von Holst, 1972). To determine whether granule cell production occurs in the dentate gyrus of adult tree shrews, immunohistochemistry for cell-specific markers and the thymidine analog bromodeoxyuridine (BrdU), a marker of DNA synthesis, was performed on the brains of adult tree shrews exposed to psychosocial stress or NMDA receptor blockade.

\section{MATERIALS AND METHODS}

\section{Animal care and treatment}

Adult ( 7 months to 2.5 years old) male tree shrews (Tupaia belangeri) from the breeding colony at the German Primate Center (Göttingen, Germany) were used in all experiments. Tree shrews are diurnal animals that reach sexual maturity between 4 and 5 months and have a lifespan of up to 12 years in captivity. All animal experimentation was conducted in accordance with the National Institutes of Health (NIH) Guide for the 
Care and Use of Laboratory Animals (NIH Publication 85-23, revised 1985 ) and were approved by the government of Lower Saxony, Germany. The animals were housed individually on a $12 \mathrm{hr} / 12 \mathrm{hr}$ light/dark cycle with artificial illumination from 8:00 A.M. to 8:00 P.M. in air conditioned rooms (for details, see Fuchs and Schumacher, 1990). All treatments were performed during the day (lights on).

\section{Experiment 1}

To determine whether cells in the dentate gyrus of adult tree shrews incorporate $\mathrm{BrdU}$ and divide, tree shrews were given a single i.p. injection of BrdU [Sigma, St. Louis, MO; $75 \mathrm{mg} / \mathrm{kg}$ in saline and $0.007 \mathrm{~N} \mathrm{NaOH}$ (this dose was used in all experiments)]. After a survival time of 2 or 24 $\mathrm{hr}$, the tree shrews ( $n=3$ for each group) were anesthetized and perfused transcardially (see below). The $2 \mathrm{hr}$ survival time allows for incorporation of BrdU by cells synthesizing DNA but not for completion of mitosis (Nowakowski et al., 1989). BrdU is available for uptake into cells synthesizing DNA for approximately $2 \mathrm{hr}$ (Packard et al., 1973). The $24 \mathrm{hr}$ survival time allows for the completion of at least one cell cycle by cells in S phase at the time of BrdU injection (Nowakowski et al., 1989).

\section{Experiment 2}

To determine whether cells that incorporate BrdU survive and express the neuronal marker neuron specific enolase (NSE), tree shrews $(n=3)$ were given a single i.p. injection of $\mathrm{BrdU}$ and were anesthetized and perfused transcardially 3 weeks later. In the dentate gyrus of the adult rat, mature granule neurons, but not glia, express NSE (Cameron et al., 1993). The majority of cells newly generated in the dentate gyrus of adult rats have been shown to express NSE by 3 weeks after incorporation of $\left[{ }^{3} \mathrm{H}\right]$ thymidine during DNA synthesis (Cameron et al., 1993).

\section{Experiment 3}

To determine whether cell proliferation can be modulated by a stressful experience, tree shrews exposed to acute psychosocial stress were examined (Fuchs et al., 1996). The experimental induction of psychosocial conflict was carried out as follows. An opaque partition between the neighboring cages of two males unknown to one another was removed. This resulted in active competition for control over the enlarged territory and the establishment of an obvious dominant/subordinate relationship. Under these conditions, the subordinate animal became virtually immobile, showed tail ruffling, and elicited alarm cries, whereas the dominant tree shrew maintained a normal level and sphere of activity. After $1 \mathrm{hr}$, the animals were separated again by the opaque partition and the subordinate tree shrews $(n=3)$ were given injections of BrdU. Subordinate tree shrews demonstrate elevated urinary cortisol levels at this time point compared with both control and dominant tree shrews (Magarinos et al., 1996). Two hours after BrdU injection, the animals were anesthetized and perfused transcardially. These animals were compared to tree shrews $(n=3)$ that were not exposed to a stressful experience but received a single $\mathrm{BrdU}$ injection, followed by a $2 \mathrm{hr}$ survival time.

\section{Experiment 4}

To determine whether the production of cells in the dentate gyrus of adult tree shrews is affected by NMDA receptor activation, tree shrews were given injections of the specific noncompetitive NMDA receptor antagonist MK-801 $(1.0 \mathrm{mg} / \mathrm{kg}$ in saline, i.p.; gift of Merck Research Laboratories, Rahway, NJ) or saline ( $n=3$ for each group). This dose has been shown to stimulate granule cell production in the dentate gyrus of adult rats (Cameron et al., 1995). Two hours after MK-801 treatment, the animals were given injections of BrdU and were anesthetized and perfused transcardially after a $2 \mathrm{hr}$ survival time.

\section{Histological procedures}

After treatments, the tree shrews received an overdose of Rompum/ Ketanest and were perfused transcardially with $4.0 \%$ paraformaldehyde in $0.1 \mathrm{M}$ phosphate buffer (PB). The heads were postfixed overnight, and the brains were removed from the skulls on the following day. Brain sections $(40 \mu \mathrm{m})$ were cut on an oscillating tissue slicer in a bath of PB.

\section{$B r d U$ and vimentin immunohistochemistry}

For BrdU immunohistochemistry, the sections were permeabilized with $0.5 \%(\mathrm{v} / \mathrm{v})$ Triton X-100 in PBS for $1 \mathrm{hr}$, incubated with Pronase E (3 $\mu \mathrm{g} / \mathrm{ml}$ ) in PBS at $37^{\circ} \mathrm{C}$ for $20 \mathrm{~min}$, denatured in $2 \mathrm{~N} \mathrm{HCL}$ for $20 \mathrm{~min}$, rinsed twice in PBS, and incubated overnight at $4^{\circ} \mathrm{C}$ with monoclonal antibody $(\mathrm{mAb})$ against BrdU (Novocastra, Newcastle upon Tyne, United
Kingdom; 1:100 in PBS). The sections were rinsed in PBS, incubated for $1 \mathrm{hr}$ in biotinylated mouse secondary antisera (Vector Laboratories, Burlingame, CA; 1:50 in PBS), rinsed in PBS, incubated for $1 \mathrm{hr}$ in avidin-biotin-horseradish peroxidase (Vector, 1:50 in PBS), rinsed in PBS, and reacted with diaminobenzidine and hydrogen peroxide in PBS. After rinsing in PBS, the sections were mounted onto gelatinized glass slides and stained for Nissl using cresyl violet.

Some brain sections that were not stained for BrdU were incubated overnight in $\mathrm{mAb}$ against vimentin (Boehringer Mannheim, Indianapolis, IN; clone V9, 1:50 in PBS). Vimentin, a cytoskeletal protein of immature astroglia, is expressed by radial glia in the dentate gyrus of adult rats (Gould et al., 1992). After this, the sections were processed for avidinbiotin-horseradish peroxidase immunohistochemistry as described above for BrdU staining.

\section{Combined BrdU and NSE immunohistochemistry}

Two different combined immunohistochemical methods were used to visualize BrdU and NSE on the same brain section. In the first method, the sections were reacted for BrdU immunohistochemistry as described above. After several rinses in PBS, the sections were incubated overnight in polyclonal antisera against NSE (Polysciences, Warrington, PA; 1:2000 in PBS). The sections were then rinsed in PBS and incubated for $2 \mathrm{hr}$ in FITC-conjugated rabbit antisera (Vector, 1:50 in PBS) with goat normal serum, rinsed again, and mounted onto gelatinized slides and coverslipped under Crystal Mount (Biomeda Corp., Foster City CA). In the second method, the sections were reacted for BrdU immunohistochemistry as described above, with the exception that the solution of diaminobenzidine and hydrogen peroxide in PBS contained $2.5 \%$ nickel sulfate. The sections were then rinsed several times in PBS and incubated overnight in polyclonal antisera against NSE (Polysciences, 1:2000 in PBS). After several rinses in PBS, the sections were incubated for $1 \mathrm{hr}$ in biotinylated rabbit antisera and reacted using the avidin-biotin-horseradish peroxidase protocol as described above.

\section{Data analysis}

For each experiment, the slides were coded before quantitative analysis, and the code was not broken until the analysis was complete. For each brain, at least six sections were selected for analysis from middle to caudal dentate gyrus (between levels A 2.0 and A 3.0; see Tigges and Shantha, 1969). For each selected section, the number of BrdU-labeled cells was counted in the dentate gyrus [the granule cell layer $(\mathrm{gcl})$ and hilus combined]. The cross-sectional area of the dentate gyrus was determined by use of a Zeiss Interactive Digitizing Analysis System (ZIDAS), and the data were expressed as densities (number of cells/ $\mathrm{mm}^{2}$ ). Means were determined for these variables, and the data were subjected to two-tailed Student's $t$ tests. For brain sections immunostained for both BrdU and NSE, the percentage of BrdU-labeled cells that were NSE-immunoreactive was determined.

\section{RESULTS}

\section{BrdU incorporation in the dentate gyrus of adult tree shrews with 2 hr or 24 hr survival times}

The dentate gyrus of tree shrews processed for BrdU immunohistochemistry at 2 and $24 \mathrm{hr}$ survival times after BrdU injection revealed BrdU-labeled cells throughout the dentate gyrus at all levels examined (Figs. 1-3). These cells were typically observed in the subgranular zone (sgz), on the border of the gcl and the hilus (Figs. 1-4), as well as within the gcl and hilus. There were no obvious differences in the distribution of BrdU-immunoreactive cells at different levels of the dentate gyrus for either time point (Figs. 1-3).

Most of the BrdU-labeled cells $(\sim 85 \%)$ had the morphological characteristics of granule cell precursors, i.e., round or oval, medium-sized cell bodies (Fig. 4). The remaining BrdUimmunoreactive cells had the morphological characteristics of glial cells, i.e., triangular or irregular, small cell bodies. Quantitative analysis revealed a significant increase in the number of BrdU-labeled cells in the dentate gyrus ( $>2$ times) between 2 and $24 \mathrm{hr}$ after BrdU injection $\left[t_{(4)}=-7.337 ; p<0.005\right.$, see Table 1]. Despite this increase in cell number, the location of the BrdUlabeled cells did not change between 2 and 24 hr (Figs. 1-3). 


\section{A 3.0}

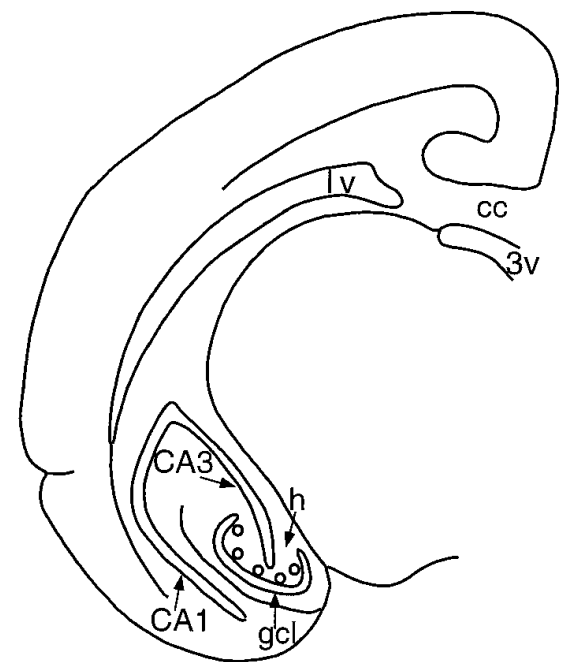

2 hours

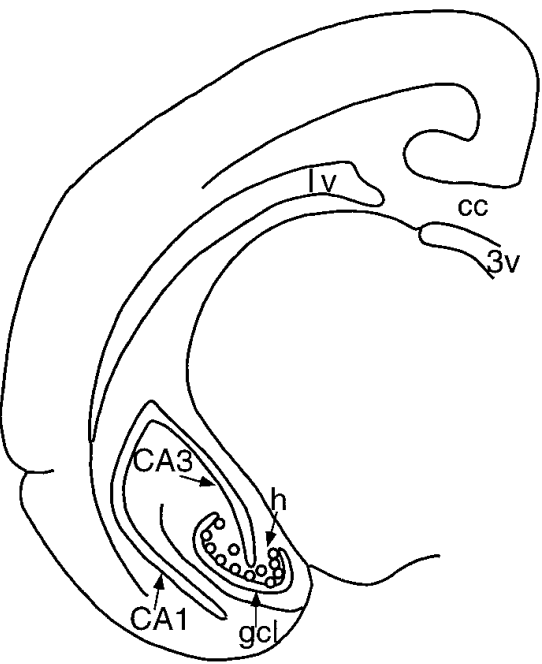

24 hours

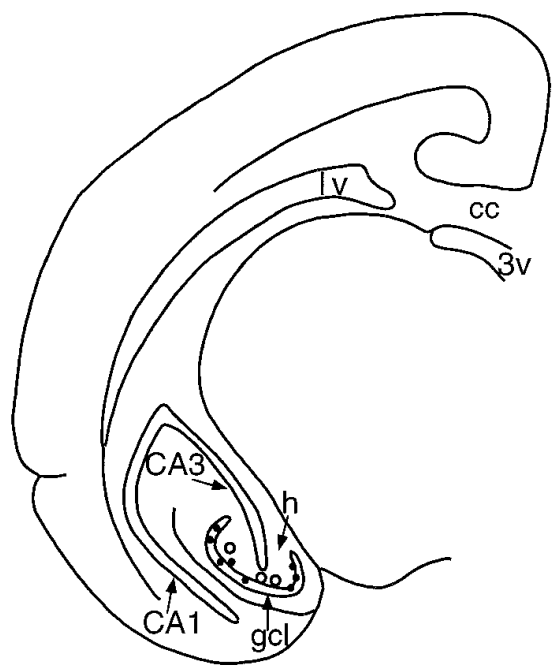

3 weeks

Figure 1. Template showing a coronal half-section of the tree shrew brain at level A 3.0 (see Tigges and Shantha, 1969), demonstrating that the number and distribution of BrdU-labeled cells (open circles) change with increased survival time after BrdU injection. Two hours after BrdU injection, most labeled cells are located in the sgz, on the border of the gcl and hilus. Twenty-four hours after BrdU injection, more than twice as many BrdU-labeled cells are observed in the dentate gyrus, predominantly in the sgz. By 3 weeks after BrdU injection, most BrdU-labeled cells are located in the gcl and express NSE (solid dots). $c c$, Corpus callosum; $l v$, lateral ventricle; $3 V$, third ventricle; $h$, hilus; $C A 1$, CA1 region; $C A 3$, CA3 region.

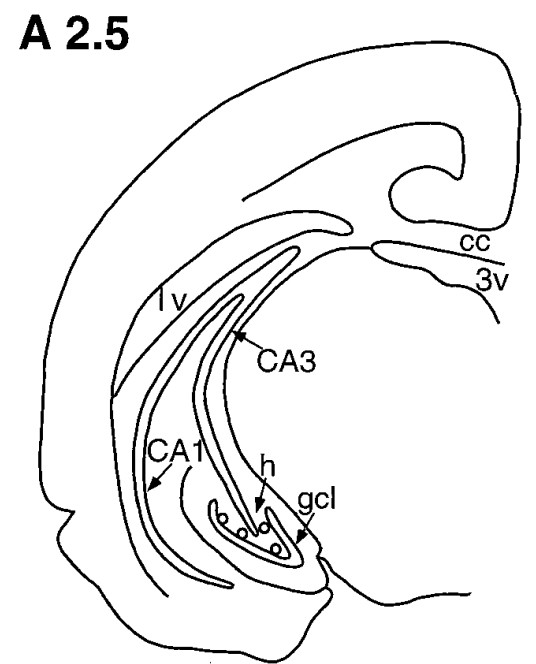

2 hours

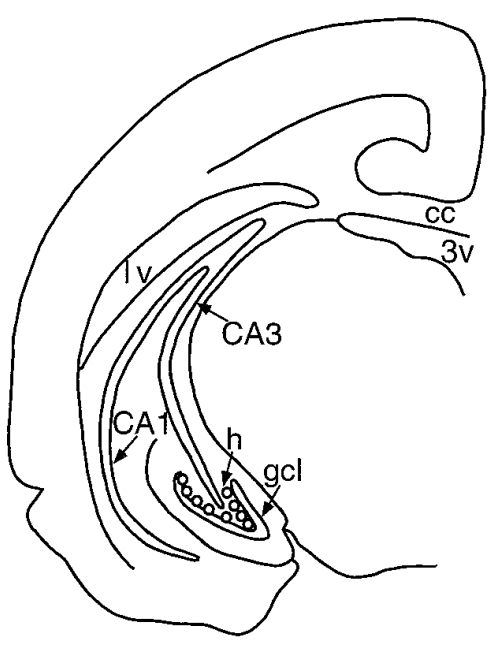

24 hours

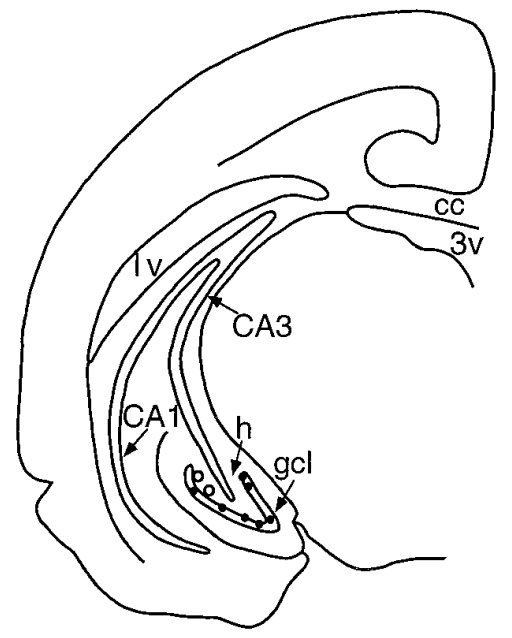

3 weeks

Figure 2. Template showing a coronal half-section of the tree shrew brain at level A 2.5 (see Tigges and Shantha, 1969), showing changes in the number and distribution of BrdU-labeled cells (open circles) with increased survival time after BrdU injection. Two hours after BrdU injection, most labeled cells are located in the sgz, between the $\mathrm{gcl}$ and hilus. Twenty-four hours after BrdU injection, more than two times as many BrdU-labeled cells are observed in the dentate gyrus, but their distribution remains similar to the $2 \mathrm{hr}$ time point. Three weeks after BrdU injection, most BrdU-labeled cells are located in the $g c l$ and are NSE-immunoreactive (solid dots). $c c$, Corpus callosum; $l v$, lateral ventricle; $3 V$, third ventricle; $h$, hilus; $C A 1$, CA1 region; $C A 3$, CA3 region.

Moreover, the cross-sectional area of the dentate gyrus did not change between 2 and $24 \mathrm{hr}$ after BrdU injection $(2 \mathrm{hr}=1.5 \pm$ $\left.0.02 \mathrm{~mm}^{2}, 24 \mathrm{hr}=1.5 \pm 0.01 \mathrm{~mm}^{2} ; p<0.4\right)$.

\section{Vimentin immunoreactivity in the dentate gyrus of adult tree shrews}

Light microscopic examination of vimentin-immunoreactive tissue revealed numerous stained cells with the morphological characteristics of radial glia, i.e., triangular shaped cell bodies with radial processes (Fig. 4). These cells were usually oriented with the cell bodies in the sgz and the processes extending through the gcl (Fig. 4). There were no detectable differences in the distribution of vimentin-immunoreactive cells at different levels of the dentate gyrus.

\section{Combined BrdU and NSE immunohistochemistry after a 3 week survival time}

Three weeks after BrdU injection, numerous BrdU-labeled cells ( $\sim 20$ per section) remained detectable in the dentate gyrus (Figs. 1-3). These cells were located predominantly in the gcl, although 


\section{A 2.0}

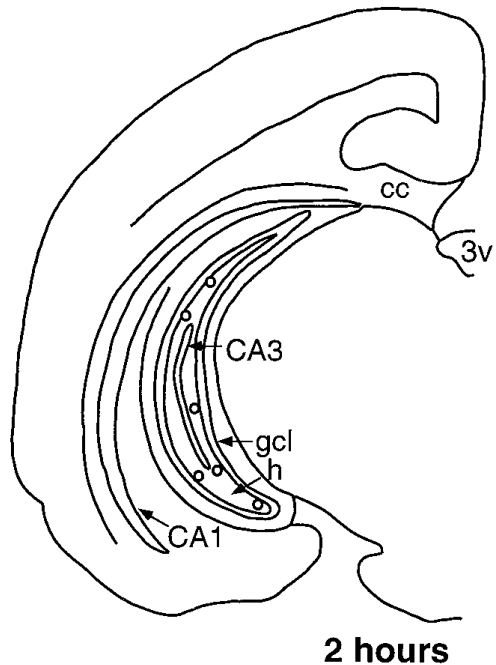

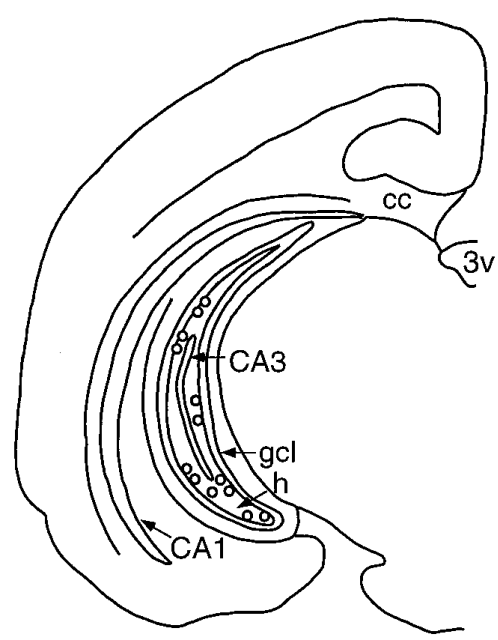

24 hours

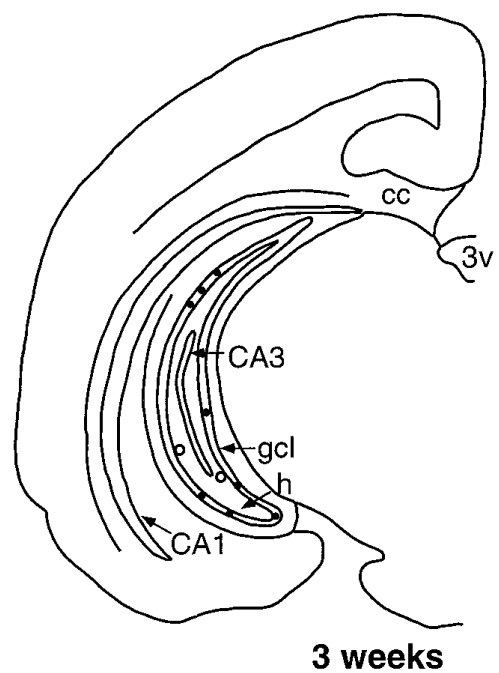

3 weeks

Figure 3. Template showing a coronal half-section of the tree shrew brain at level A 2.0 (see Tigges and Shantha, 1969), indicating changes in the number and distribution of BrdU-labeled cells (open circles) with increased survival time after BrdU injection. Most BrdU-labeled cells are located in the sgz, between the $g c l$ and hilus at the 2 and $24 \mathrm{hr}$ time points. Three weeks after BrdU injection, most BrdU-labeled cells are located in the gcl and are NSE-immunoreactive (solid dots). cc, Corpus callosum; $3 V$, third ventricle; $h$, hilus; $C A 1$, CA1 region; $C A 3$, CA3 region.
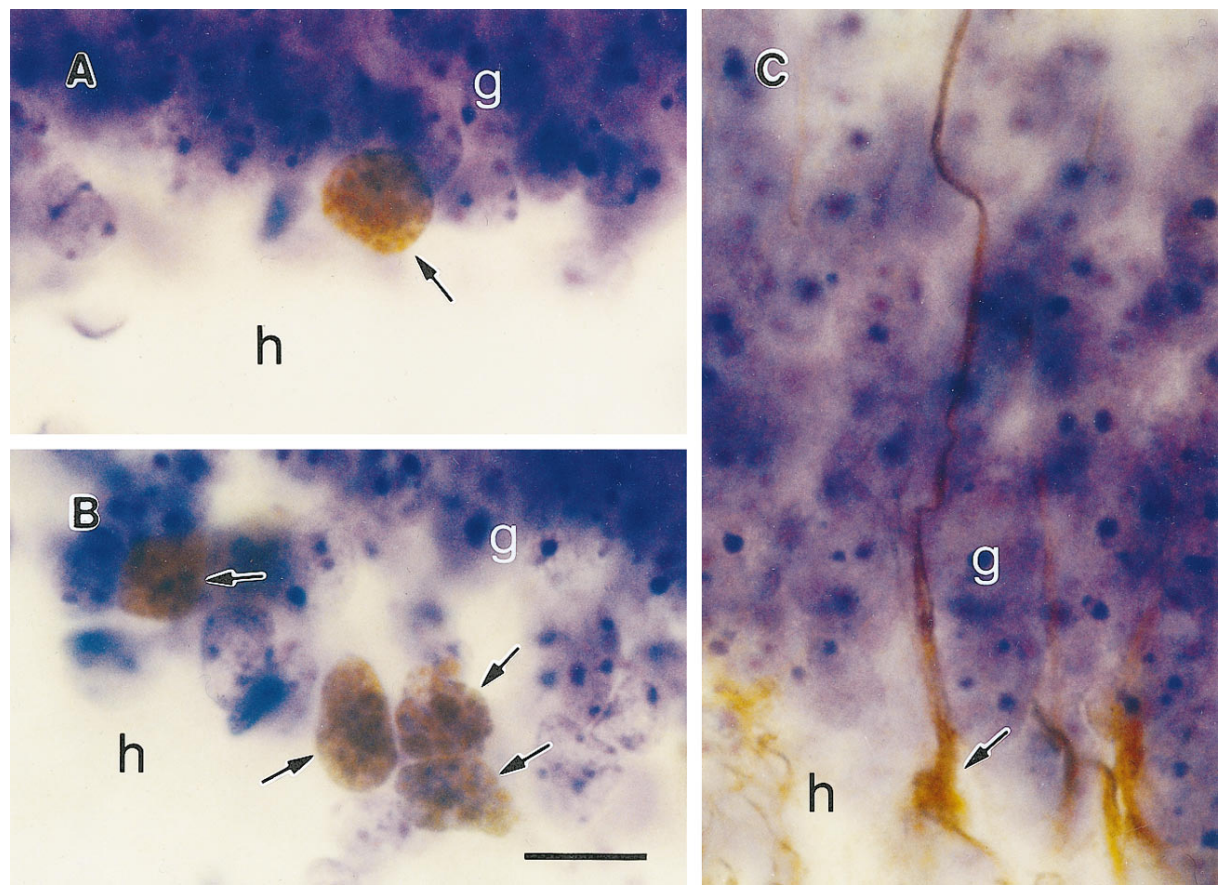

Figure 4. Examples of cell types in the dentate gyrus of the adult tree shrew. $A$, BrdUlabeled cell (arrows) in the sgz of the dentate gyrus with morphological characteristics of granule cell precursor, i.e., round or oval medium-sized cell body. $B$, Cluster of BrdUlabeled cells (arrows) in the sgz of the dentate gyrus after MK-801 treatment. $C$, Vimentinimmunoreactive cell with radial glial morphology, i.e., irregular shaped cell body with radial process. The cell body is located on the border of the hilus and gcl, and the process extends through the gcl. $g$, Granule cell layer; $h$, hilus. Scale bar in $B, 20 \mu \mathrm{m}$ (applies to all frames).

a few remained in the sgz and hilus. Both immunohistochemical methods for double labeling BrdU and NSE yielded similar results; $\sim 80 \%$ of the BrdU-labeled cells were NSEimmunoreactive. All of the cells that were labeled with BrdU and NSE were located in the gcl (Figs. 1-3) and had the morphological characteristics of granule neurons.

\section{Effects of psychosocial stress on the number of BrdU- labeled cells in the dentate gyrus}

Exposure to a single episode of acute psychosocial stress that lasted $1 \mathrm{hr}$ resulted in a significant decrease in the density of BrdU-labeled cells in the dentate gyrus compared to unstressed controls $\left[t_{(4)}=-3.807 ; p<0.05\right.$; Table 1]. No change in the cross-sectional area of the dentate gyrus was observed after acute psychosocial stress (control $=1.5 \pm 0.5 \mathrm{~mm}^{2}$, stress $=1.2 \pm 0.4$ $\left.\mathrm{mm}^{2} ; p<0.4\right)$, indicating that this difference reflects a change in the number of proliferating cells. The morphological characteristics of BrdU-labeled cells did not differ between the tree shrews subjected to psychosocial stress and unstressed control animals.

\section{Effects of NMDA receptor antagonist treatment on the number of BrdU-labeled cells in the dentate gyrus}

Treatment with the NMDA receptor antagonist MK-801 resulted in a significant increase in the density of BrdU-labeled cells in the dentate gyrus $\left[t_{(4)}=-2.945, p<0.05\right.$; Table 1$)$. No change in the cross-sectional area of the dentate gyrus was observed after MK- 
Table 1. The number of proliferating cells in the dentate gyrus of adult tree shrews at different survival times after BrdU injection, as well as after psychosocial stress or MK-801 treatment

Number of BrdU-labeled cells in the dentate gyrus $/ \mathrm{mm}^{2}$

\begin{tabular}{|c|c|c|c|c|c|}
\hline \multicolumn{2}{|c|}{ Time course experiment } & \multicolumn{2}{|c|}{ Stress experiment } & \multicolumn{2}{|c|}{ MK-801 experiment } \\
\hline $2 \mathrm{hr}$ & $24 \mathrm{hr}$ & Control & Subordinate & Control & MK-801 \\
\hline $7.9 \pm 1.5$ & $22.7 \pm 1.3^{*}$ & $6.8 \pm 1.3^{*}$ & $1.6 \pm 0.3^{*}$ & $11.8 \pm 2.1$ & $19.8 \pm 1.7^{*}$ \\
\hline
\end{tabular}

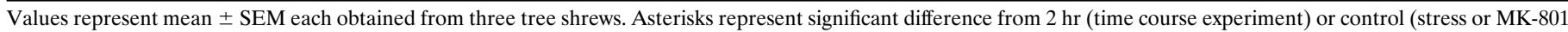
experiment); $p<0.05$, unpaired Student's $t$ tests.

801 treatment $\left(\right.$ control $=1.4 \pm 0.3 \mathrm{~mm}^{2} ;$ MK-801-treated $=1.1 \pm$ $\left.0.2 \mathrm{~mm}^{2} ; p<0.4\right)$. In MK-801-treated tree shrews, BrdU-labeled cells had morphological characteristics that were similar to those of controls, and these cells were often observed in clusters of 3-5 on the border of the gcl and hilus (Fig. 4).

\section{DISCUSSION}

The results of this report demonstrate that cells in the dentate gyrus of adult tree shrews incorporate BrdU, a marker of DNA synthesis that labels proliferating cells and their progeny. The observation that the number of BrdU-labeled cells more than doubles between 2 and $24 \mathrm{hr}$ suggests that cells synthesizing DNA in the dentate gyrus divide at least once within a $24 \mathrm{hr}$ period. Furthermore, the detection of BrdU-labeled cells that express a neuronal marker and have granule cell morphology 3 weeks after BrdU incorporation suggests that many proliferating cells in the dentate gyrus of adult tree shrews eventually become granule neurons. Moreover, the presence of radial glia with cell bodies in the sgz and processes extending through the gcl, as well as the change in location of BrdU-labeled cells from $24 \mathrm{hr}$ to 3 weeks, suggests that newly generated cells migrate from the hilus or sgz to the gcl. Finally, these results also show that the production of cells in the dentate gyrus of adult tree shrews can be modulated rapidly by exposure to a stressful social encounter, as well as by changing the level of NMDA receptor activation.

\section{Granule cell generation across mammalian species}

Previous studies have demonstrated several characteristics of dentate gyrus granule cell production that are common to numerous mammalian species, from rats to rhesus monkeys. First, granule cell production occurs during an extended period that begins during gestation and continues into the postnatal period (Schlessinger et al., 1975; Rakic and Nowakowski, 1981; Altman and Bayer, 1990a,b). This feature seems to be unrelated to the degree of maturity at birth as both altricial species (e.g., the rat) and precocial species (e.g., the guinea pig) demonstrate this phenomenon (Altman and Das, 1967; Schlessinger et al., 1975). Second, suprapyramidal to infrapyramidal and outside-in gradients of granule cell generation exist (Schlessinger et al., 1975; Rakic and Nowakowski, 1981). Third, the location of granule cell precursors changes during development; precursor cells originate in the subependymal layer, next reside in the hilus, and finally in the sgz (Rakic and Nowakowski, 1981; Altman and Bayer, 1990a,b). However, there are characteristics of granule cell production that are not shared by all mammals examined. One prominent difference in granule cell generation between the rat and the monkey is in the developmental stage at which the majority of neurons are produced. In the rat, most $(\sim 80 \%)$ granule cells are produced postnatally, whereas in the rhesus monkey, most are produced prenatally (Schlessinger et al., 1975; Rakic and Nowakowski, 1981).
The extension of granule neuron production into adulthood has been well documented in the rat (Kaplan and Bell, 1984; Stanfield and Trice, 1988; Cameron et al., 1993; Okano et al., 1993) and recently demonstrated in the meadow vole, another species of rodent (Galea and McEwen, 1995). In contrast, few studies have investigated the possibility that adult neurogenesis occurs in the dentate gyrus of nonrodent mammalian species. One report dismissed the possibility that granule cells are produced in adulthood in the dentate gyrus of rhesus monkeys and suggested that adult neurogenesis is a phenomenon unique to rats, particularly strains that increase in size throughout life (Eckenhoff and Rakic, 1988). However, it is unlikely that considerable growth in adulthood is the basis for adult neurogenesis because the guinea pig, an animal that undergoes little brain growth during the postnatal period, appears to produce granule neurons in adulthood (Altman and Das, 1967). Rather, it appears that the mammalian dentate gyrus is a specialized brain region in which neurogenesis continues into adulthood regardless of the developmental pattern of the animal. In light of recent findings, the possibility that adult neurogenesis occurs in the dentate gyrus of most mammals, including other primate species, should be reconsidered. First, the results of this study have demonstrated granule neuron production and its regulation by neural activity and behavioral events in the dentate gyrus of the adult tree shrew. Second, we have observed BrdUlabeled cells with the morphology of immature granule neurons, as well as vimentin-immunoreactive radial glia, in the dentate gyrus of adult marmoset monkeys (Callithrix jacchus) and an adult cynomolgus (Macaca fascicularis) monkey (our unpublished observations). Moreover, the recent observations that precursor cells capable of generating neurons exist in the subependymal layer of adult humans (Kirschenbaum et al., 1994) suggest a reevaluation of the limits of neurogenesis across species in other regions as well.

\section{Significance of radial glia in the adult brain}

During development, radial glia are believed to participate in the migration of immature neurons from their site of origin to their final destination. The results of this study and our previous report (Gould et al., 1992) indicate that the dentate gyrus maintains a population of radial glia in adulthood in both the tree shrew and rat. In addition, cells produced in the dentate gyrus of both the tree shrew and the rat (Cameron et al., 1993) move from the hilus or sgz to the gcl after DNA synthesis, suggesting that radial glia guide migrating granule cells in adulthood. It should be noted, though, that the processes of radial glia are considerably longer than the distances immature granule cells appear to migrate in the adult. A recent report indicates that radial glia in the dentate gyrus of adult rats are associated with the dendrites of immature granule neurons (Seki and Arai, 1996), presenting the possibility 
that radial glia may serve other developmental functions, in addition to migration, such as supporting the growing dendritic tree.

\section{NMDA receptor activation regulates cell proliferation}

The results of this study also suggest that intrinsic factors regulating the production of granule neurons in the adult dentate gyrus may be common to mammalian species that undergo adult neurogenesis. Treatment with MK-801, a noncompetitive NMDA receptor antagonist, resulted in a rapid increase in the number of cells synthesizing DNA, suggesting that NMDA receptor activation normally inhibits cell proliferation in the dentate gyrus of the tree shrew. These results are consistent with our previous studies demonstrating that NMDA receptor blockade or activation increases or decreases, respectively, the production of granule cells in the dentate gyrus of adult rats (Cameron et al., 1995). Excitation may inhibit neurogenesis by preventing the synthesis or release of mitogenic factors from cells in the vicinity of precursor cells. Several studies have shown that stressful experiences rapidly stimulate glutamate release and alter the expression of NMDA receptors in the hippocampus of the rat (Krugers et al., 1993; Moghaddam et al., 1994; Bartanusz et al., 1995). Collectively, these results suggest that stressful experiences inhibit the production of granule neurons via actions on excitatory pathways to the dentate gyrus.

\section{Psychosocial stress inhibits cell proliferation}

The functional consequences of adult neurogenesis in the dentate gyrus are presently unknown. One approach to elucidating the function of granule neuron production in adulthood is to identify the factors that regulate its occurrence. The results of this study have shown that a brief exposure to psychosocial stress, during which a dominant/subordinate relationship is established, results in a rapid decrease in the number of cells that incorporate BrdU in the dentate gyrus of the subordinate animal. After a single encounter with a dominant tree shrew, the subordinate will remain in a constant state of arousal in the presence of the dominant animal. This stress reaction is characterized by a reduced sphere of activity, vigilance, alarm cries, and tail ruffling (von Holst, 1972). When removed from the presence of the dominant after the initial encounter, subordinate tree shrews will recover physically but will demonstrate immediate stress reactions after subsequent exposures to the dominant (von Holst, 1972), indicating that a potent memory of the experience has been formed. Because the hippocampus has been implicated in spatial learning and memory (Sutherland et al., 1983; Wishaw, 1987; McNaughton et al., 1989), as well as in contextual learning in conditioned fear paradigms (Phillips and LeDoux, 1992), it is possible that stressinduced stabilization of the granule cell population may be necessary for learning during a threatening social encounter. The production of new granule neurons for increased storage capacity may be permitted only during periods of low stress when learning is not critical.

In the tree shrew, the stress of subordination is mediated by visual and not olfactory cues; exposure to the olfactory markings or the odor of the dominant does not elicit a reaction (von Holst, 1972). We have shown that exposure of adult rats to fox odor, which increases both adrenal steroid levels and excitatory input (Heale et al., 1994; Vernet-Maury et al., 1984), rapidly inhibits cell proliferation in the dentate gyrus (Galea et al., 1996). Collectively, these findings suggest that rapid suppression of cell proliferation by a threatening experience, conveyed via cues from different sensory modalities, is a characteristic of the dentate gyrus that is common to mammalian species that undergo adult neurogenesis.

\section{REFERENCES}

Altman J, Bayer SA (1990a) Mosaic organization of the hippocampal neuroepithelium and the multiple germinal sources of dentate granule cells. J Comp Neurol 301:325-342.

Altman J, Bayer SA (1990b) Migration and distribution of two populations of hippocampal granule cell precursors during the perinatal and postnatal periods. J Comp Neurol 301:365-381.

Altman J, Das GD (1967) Postnatal neurogenesis in the guinea-pig. Nature 214:1098-1101.

Angevine JB (1965) Time of neuron origin in the hippocampal region: an autoradiographic study in the mouse. Exp Neurol 2:1-17.

Bartanusz V, Aubry J-M, Pagliusi S, Jezova D, Baffi J, Kiss JZ (1995) Stress-induced changes in messenger RNA levels of $N$-methyl-Daspartate and AMPA receptor subunits in selected regions of the rat hippocampus and hypothalamus. Neuroscience 66:247-252.

Cameron HA, Gould E (1994) Adult neurogenesis is regulated by adrenal steroids in the dentate gyrus. Neuroscience 61:203-209.

Cameron HA, McEwen BS, Gould E (1995) Regulation of adult neurogenesis by excitatory input and NMDA receptor activation in the dentate gyrus. J Neurosci 15:4687-4692.

Cameron HA, Woolley CS, McEwen BS, Gould E (1993) Differentiation of newly born neurons and glia in the dentate gyrus of the adult rat. Neuroscience 56:337-344.

Eckenhoff MF, Rakic P (1988) Nature and fate of proliferative cells in the hippocampal dentate gyrus during the life span of the rhesus monkey. J Neurosci 8:2729-2747.

Fuchs E, Schumacher M (1990) Psychosocial stress affects pineal function in the tree shrew (Tupaia belangeri). Physiol Behav 47:713-717.

Fuchs E, Kramer M, Hermes B, Netter B, Hiemke C (1996) Psychosocial stress in tree shrews: clomipramine counteracts behavioral and endocrine changes. Pharmacol Biochem Behav 54:219-228.

Galea LAM, McEwen BS (1995) Sex differences in adult neurogenesis in the wild-trapped meadow vole. Soc Neurosci Abstr 21:1287.

Galea LAM, Tanapat P, Gould E (1996) Exposure to predator odor suppresses cell proliferation in the dentate gyrus of adult rats via a cholinergic mechanism. Soc Neurosci Abstr 22:1196.

Gould E, Cameron HA, Daniels DC, Woolley CS, McEwen BS (1992) Adrenal hormones suppress cell division in the adult rat dentate gyrus. J Neurosci 12:3642-3650.

Gueneau G, Privat A, Drouet J, Court L (1982) Subgranular zone of the dentate gyrus of young rabbits as a secondary matrix. Dev Neurosci 5:345-358.

Heale VR, Vanderwolf CH, Kavaliers M (1994) Components of weasel and fox odors elicit fast wave bursts in the dentate gyrus of rats. Behav Brain Res 63:159-165.

Kaplan MS, Bell DH (1984) Mitotic neuroblasts in the 9-day-old and 11-month-old rodent hippocampus. J Neurosci 4:1429-1441.

Kaplan MS, Hinds JW (1977) Neurogenesis in the adult rat: electron microscopic analysis of light radioautographs. Science 197:1092-1094.

Kirschenbaum B, Nedergaard M, Preuss A, Barami K, Fraser RA, Goldman SA (1994) In vitro neuronal production and differentiation by precursor cells derived from the adult human forebrain. Cereb Cortex 4:576-589.

Krugers HJ, Koolhaas JM, Bohua B, Korf J (1993) A single stress experience alters glutamate receptor-binding in rat hippocampal CA3 area. Neurosci Lett 154:73-77.

Kuhn HG, Dickinson-Anson H, Gage FH (1996) Neurogenesis in the dentate gyrus of the adult rat: age-related decrease in neuronal progenitor population. J Neurosci 16:2027-2033.

Magarinos AM, McEwen BS, Flugge G, Fuchs E (1996) Chronic psychosocial stress causes apical dendritic atrophy of hippocampal CA3 pyramidal neurons in subordinate tree shrews. J Neurosci 16:3534-3540.

Martin RD (1990) Primate origins and evolution. London: Chapman \& Hall.

McNaughton BL, Barnes CA, Meltzer J, Sutherland RJ (1989) Hippocampal granule cells are necessary for normal spatial learning but not for spatially-selective pyramidal cell discharge. Exp Brain Res 76:485-496.

Moghaddam B, Boliano ML, Stein-Behrens B, Sapolsky R (1994) Glucocorticoids mediate the stress-induced extracellular accumulation of glutamate. Brain Res 655:251-154.

Nowakowski RS, Lewin SB, Miller MW (1989) Bromodeoxyuridine immunohistochemical determination of the lengths of the cell cycle and the DNA-synthetic phase for an anatomically defined population. J Neurocytol 18:311-318. 
Okano HJ, Pfaff DW, Gibbs RB (1993) RB and Cdc2 expression in brain: correlations with $\left[{ }^{3} \mathrm{H}\right]$ thymidine incorporation and neurogenesis. J Neurosci 13:2930-2938.

Packard DS, Menzies RA, Skalko RG (1973) Incorporation of thymidine and its analog, bromodeoxyuridine, into embryos and maternal tissues of the mouse. Differentiation 1:397-405.

Phillips RG, LeDoux JE (1992) Differential contribution of amygdala and hippocampus to cued and contextual fear conditioning. Behav Neurosci 106:274-285.

Rakic P, Nowakowski RS (1981) The time of origin of neurons in the hippocampal region of the rhesus monkey. J Comp Neurol 196:99-128.

Schlessinger AR, Cowan WM, Gottlieb DI (1975) An autoradiographic study of the time of origin and the pattern of granule cell migration in the dentate gyrus of the rat. J Comp Neurol 159:159-176.

Seki T, Arai Y (1996) Dendritic development of newly-generated granule cells in the adult hippocampus occurs upon contact with radial glia-like cells. Soc Neurosci Abstr 22:534.

Stanfield BB, Trice JE (1988) Evidence that granule cells generated in the dentate gyrus of adult rats extend axonal projections. Exp Brain Res 72:399-406.
Sutherland RJ, Whishaw IQ, Kolb B (1983) A behavioural analysis of spatial localization following electrolytic, kainate- or colchicine-induced damage to the hippocampal formation in the rat. Behav Brain Res 7:133-153.

Tigges J, Shantha TR (1969) A stereotaxic atlas of the tree shrew (Tupaia glis). Baltimore: Williams \& Wilkins.

Vernet-Maury E, Polak EH, Demael A (1984) Structure-activity relationship of stress-inducing odorants in the rat. J Chem Ecol 10:1007-1019.

von Holst D (1972) Social stress in the tree-shrew: its causes and physiological and ethological consequences. In: Prosimian biology (Martin RD, Doyle GA, Walker AC, eds), pp 389-411. Philadelphia: University of Pittsburgh.

Whishaw IQ (1987) Hippocampal, granule cell and CA3-4 lesions impair formation of a place learning-set in the rat and induce reflex epilepsy. Behav Brain Res 24:59-72.

Wyss JM, Sripanidkulchai B (1985) The development of Ammon's horn and the fascia dentata in the cat: a $\left[{ }^{3} \mathrm{H}\right]$ thymidine analysis. Brain Res 350:185-198. 